\title{
Proposição de critérios para avaliação e delimitação de bacias hidrogeológicas
}

\author{
Tássia de Melo Arraes ${ }^{1}$ \& José Elói Guimarães Campos ${ }^{2}$
}

\begin{abstract}
Resumo A designação de "bacia hidrogeológica" ainda necessita ser complementada com relação aos aspectos de sua conceituação e aplicação. Um dos enfoques desprovidos de embasamento teórico e conceitual diz respeito aos critérios para definição dos limites das bacias hidrogeológicas e as relações com as bacias hidrográficas sobrepostas. A literatura técnica atualmente disponível a esse respeito é muito restrita e incompleta. Assim o objetivo do presente trabalho é contribuir com o conhecimento sobre as bacias hidrogeológicas, bem como caracterizar uma terminologia a ser utilizada para futuros estudos hidrogeológicos em áreas específicas. Dentre as principais técnicas aplicadas à delimitação das bacias hidrogeológicas destacam-se os estudos de piezometria, hidrologia, hidroquímica, ensaios de traçadores e geofísica, e, dentre suas principais aplicações e implicações podem ser citadas a gestão integrada dos recursos hídricos, o estudo de aqüíferos transfronteiriços, a definição do perímetro de proteção dos poços e o estudo de remediação de aqüíferos contaminados.
\end{abstract}

Palavras-chave: bacias hidrográficas, bacias hidrogeológicas/subterrâneas, delimitação, gestão.

\begin{abstract}
Criteria to the determination and evaluation of hydrogeologic basin The designation of the "hydrogeologic basin" terminology still needs to be complemented regarding the definition and application aspects. One of the approaches without theoretical and conceptual basement is related to the criteria for definition the boundaries of the hydrogeologic basins and the relationships with the overland watersheds. The available technical literature is very restricted and incomplete. Because of this, the objective of the present paper is to contribute with the knowledge on the hydrogeologic basins, as well as to characterize a terminology to be used for futures hydrogeologic studies. Potenciometric surfaces mapping, hydrology, hidrochemistry, tracing tests and geophysics are among the main applied techniques to the delimitation of the hydrogeologic basins. The integrated wate resource management, the study of borders aquifers, the definition of well protection perimeter and the remediation study on polluted aquifers are some of the cases where the knowledge of the hydrogeologic boundaries is very important.
\end{abstract}

Keywords: watershed, hydrogeologic/groundwater basin, delimitation, management.

INTRODUÇÃ̃O Em estudos hidrológicos e de demais fenômenos do fluxo superficial, a unidade principal de investigação é a bacia hidrográfica (Rennó 2004). Dessa forma, muitos dos critérios utilizados para a delimitação da unidade hidrográfica são bem conhecidos e contam inclusive com modelos digitais já desenvolvidos que permitem, a partir da existência de curvas de nível, a delimitação automática das bacias e do sentido do escoamento superficial em qualquer ponto da poligonal da bacia (Rennó \& Soares 2001). Referências bibliográficas são comumente encontradas com respeito aos critérios para delimitação e gestão das bacias hidrográficas.

Com relação às bacias hidrogeológicas, ao contrário, a literatura é muito restrita e de certa forma deficiente. Tiedman et al. (1998) definem bacia hidrogeológica como os limites e caminhos que a água subsuperficial segue através do aqǘf́ro, desde as zonas de recarga até um exutório específico. Segundo a resolução Número 15, do Conselho Nacional de Recursos Hídricos (CNRH 2001), um corpo hídrico subter- râneo corresponde ao volume de água armazenado no subsolo, onde os aqüíferos podem apresentar zonas de descarga e recarga pertencentes a uma ou mais bacias hidrográficas sobrejacentes.

As informações hidrogeológicas existentes representam importante subsídio para direcionar pesquisas e auxiliar na escolha das melhores alternativas de ação com relação à gestão integrada dos recursos hídricos. Além disso, devido a crescente necessidade da utilização racional da água subterrânea e de diversas outras questões, muitas vezes até de âmbito político, torna-se cada vez mais importante aprimorar o conhecimento acerca das bacias hidrogeológicas.

No caso dos aqüíferos subjacentes a duas ou mais unidades federativas, por exemplo, é necessário um bom conhecimento prévio dos limites da bacia hidrogeológica para que os possíveis conflitos existentes e potenciais sejam resolvidos de maneira coerente.

Portanto, o objetivo do presente estudo é o refinamento da conceituação do termo bacia hidrogeológica e a proposição de elementos diagnósticos que auxi- 
liem na definição de seus limites e, conseqüentemente, na viabilização de iniciativas como a gestão integrada das águas superficiais e subterrâneas.

DEFINIÇÃO Uma bacia hidrográfica é uma unidade fisiográfica constituída de um sistema de rios que drenam uma área topograficamente definida, representada pelo divisor de águas (Clark et al. 2005). A bacia hidrográfica associada a uma dada seção fluvial é limitada pelos seus divisores de água e pela rede de drenagem. Assim, a individualização de bacias hidrográficas pode ser feita simplesmente a partir da análise de cartas topográficas ou fotografias aéreas.

Já as bacias hidrogeológicas não são tão prontamente reconhecidas, sendo necessária a utilização de diversos métodos para estabelecer a sua real extensão lateral. Há casos em que uma bacia hidrogeológica possui área muito maior que a da respectiva bacia hidrográfica (Tiedman et al. 1998.), podendo incluir inúmeras bacias hidrográficas sobrejacentes com diversos divisores e compartimentação interna distinta, com diferentes tipos de padrões de drenagem, variação na densidade da drenagem, forma e dissecação do relevo, forma da encosta e comprimento de rampas (Fig. 1). Por outro lado, existem casos em que uma mesma bacia hidrográfica pode definir, em subsuperfície, diferentes padrões de fluxo de forma que águas que infiltram apresentem padrões divergentes do fluxo interno e do escoamento de base, com relação ao escoamento superficial (Fig. 2).

A assimetria entre os limites das bacias hidrográficas e hidrogeológicas pode ser controlada por vários parâmetros com destaque para: heterogeneidades dos aqüíferos, anisotropia em sistemas aqüíferos fraturados e cársticos, variação brusca da potenciometria em situações de limites laterais de aqüíferos, presença de estruturas geológicas de grande porte (dobras ou falhas), presença de aqüíferos com diferente tipo de porosidade sobrepostos, além de outros ou mesmo da associação desses fatores (Fig. 3).

O termo bacia hidrogeológica ou subterrânea é definido nesse trabalho como o limite entre as zonas de recarga e descarga de determinado aqüífero, sendo a zona de recarga considerada a partir da região onde as águas ou plumas descendentes de umidade alcançam o topo da zona saturada dos aqüíferos e os exutórios os pontos ou áreas onde as águas retornam à superfície. Como o aqüífero é tridimensional, a região de recarga constituirá uma área e os limites da bacia hidrogeológica serão representados por linhas que fecham em um polígono, a exemplo do que ocorre na bacia hidrográfica.

A partir da definição proposta, fica claro que o funcionamento hídrico de uma bacia hidrogeológica é sensivelmente diferente daquele observado para uma bacia hidrográfica. Os limites de uma bacia hidrográfica são definidos a partir de um ponto no exutório, de forma que toda a área drenada a montante do ponto escolhido define a bacia em questão. A própria definição de bacias e sub-bacias é facilitada (Fig. 4). No caso da bacia hidrogeológica, o exutório não pode ser definido como um ponto, sendo geralmente caracterizado por uma área ou pelo menos por uma linha de descarga, de forma que a limitação da área da bacia se torna ainda mais complexa (Fig. 5).

\section{CRITÉRIOS PARA DELIMITAÇÃO DE BACIAS HIDROGEOLÓGICAS Para solucionar os possí-} veis problemas de assimetria entre bacias hidrográficas e hidrogeológicas, propõe-se a aplicação das seguintes metodologias: estudos hidrológicos, estudos potenciométricos, ensaios de traçador, geoquímica isotópica, análise de lineamentos e estudos geofísicos. Os métodos e técnicas propostos podem, em alguns casos, defi-

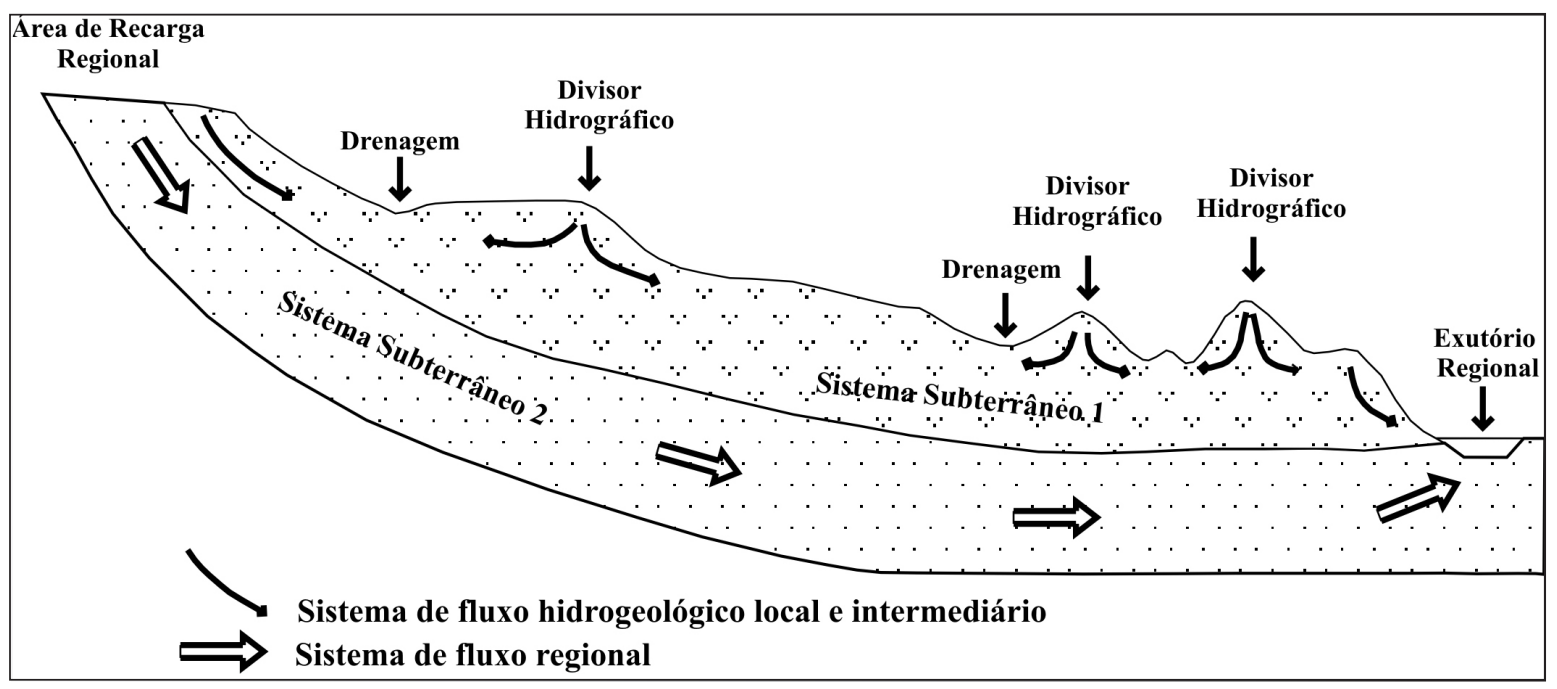

Figura 1 - Exemplo de situação em que duas bacias hidrogeológicas (sistemas subterrâneos 1 e 2) são sobrepostas por inúmeras bacias hidrográficas. No sistema subterrâneo 1 ocorrem sistemas de fluxo hidrogeológico locais e intermediários e no sistema subterrâneo 2 ocorre sistema de fluxo regional. 


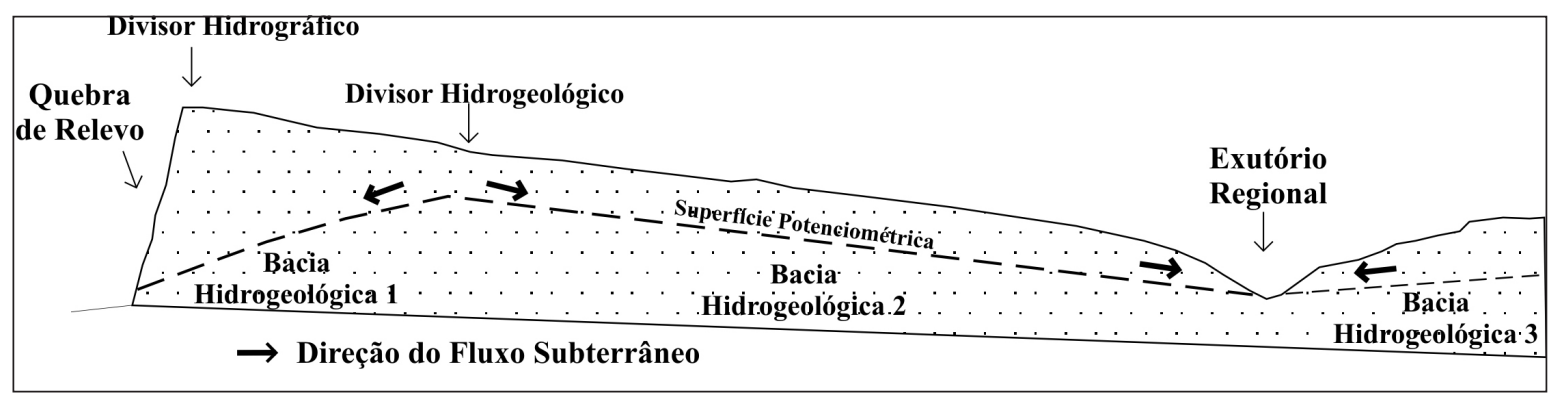

Figura 2 - Exemplo de assimetria entre bacias subterrâneas e superficiais, onde uma única bacia hidrográfica apresenta pelo menos três bacias hidrogeológicas em profundidade.

nir de forma qualitativa a assimetria entre as bacias, ou em outros casos definir com precisão seus limites.

A definição precisa dos limites entre bacias hidrogeológicas deve transcender os limites físicos entre tipos de rochas, fácies hidrogeológicas e estruturas, mas deve também considerar os aspectos do tipo de fluxo hidrogeológico e regime hídrico da rede de drenagem superficial (rios efluentes ou influentes).

Idealmente, devem ser empregados métodos associados entre si e quanto maior a escala de trabalho maior o número de dados necessários para uma delimitação precisa.

Estudos Potenciométricos A água subterrânea movimenta-se através de poros ou vazios originalmente presentes na rocha (porosidade primária) ou através de fissuras e cavidades de dissolução criadas após a sua formação (porosidade secundária). Essa movimentação da água subterrânea forma um fluxo cujo sentido pode ser obtido através do potencial hidráulico de poços de monitoramento (Cabral 1997). Conhecendo-se o valor do potencial hidráulico de cada poço, as linhas de fluxo devem seguir dos pontos de maior potencial para os de menor potencial.

Segundo Feitosa (1997), a superfície potenciométrica pode ser entendida como o lugar geométrico dos pontos que marcam as alturas potenciométricas de um dado aqüífero, referentes a uma profundidade específica. Essa superfície permite estudar as características do movimento das águas subterrâneas, os eixos e as direções de fluxo da água. As curvas de igual altitude da superfície piezométrica são denominadas curvas isopiezas e a partir delas, pode-se construir mapas potenciométricos obtidos através de medição em campo dos níveis piezométricos com posterior análise e interpretação sobre mapas topográficos. Esses mapas possibilitam a visualização bidimensional da direção do fluxo além de proporcionarem subsídios para a delineação de considerações a respeito do gradiente hidráulico e vazão unitária de uma dada região.

A análise de fluxo corresponde, portanto, a um importante parâmetro a ser considerado na determinação dos limites de bacias hidrogeológicas uma vez que, através da construção de mapas de isopiezas pode-se estabelecer as direções do fluxo da água em bacias hidrogeológicas e compará-los com o de bacias hidrográ- ficas.

Os estudos potenciométricos resultam nos dados mais importantes para a delimitação das bacias hidrogeológicas.

Estudos Hidrológicos Duas drenagens, integrantes de sub-bacias próximas, que apresentem áreas e condições geomorfológicas, pedológicas, climáticas e pluviométricas semelhantes, porém diferentes medidas de vazão específica, podem não pertencer à uma mesma bacia hidrogeológica, mesmo que pertençam à mesma bacia hidrográfica. Isso ocorre por que existem heterogeneidades e anisotropias no meio geológico subjacente que fazem com que as medidas de vazão sejam diferentes do esperado a partir da análise fisiográfica do terreno.

Se considerado o caso de duas drenagens encaixadas em vales separados por um alto topográfico, essas heterogeneidades poderiam ser provocadas, por exemplo, pela ocorrência de camadas isolantes que drenam o fluxo de água que infiltra no meio para o lado oposto ao esperado em função do relevo (Fig. 3D). Assim, grande parte da água é drenada para um curso d'água em detrimento do outro, que apresentará medidas de vazão mais reduzidas e com menor regularização. Nesse caso as medidas de vazão específica representam uma evidência que comprova o fato de que os limites das bacias hidrográfica e hidrogeológica poderiam ser distintos.

Os resultados das avaliações hidrológicas não possibilitam a determinação precisa dos limites da bacia hidrogeológica, mas podem mostrar possíveis casos de assimetria entre as bacias em superfície e em subsuperfície.

Ensaios de Traçador $\mathrm{Na}$ pesquisa hidrogeológica comumente utilizam-se isótopos estáveis e radioativos (Feitosa 1997). Os isótopos estáveis ocorrem em quantidade definida na natureza enquanto os radioativos passam por um processo de decaimento, tendo a sua quantidade diminuída com relação ao avanço do tempo.

Os isótopos estáveis são usualmente utilizados como traçadores em estudos de condições de fluxo subterrâneo (Feitosa 1997). O traçador corresponde a uma determinada massa de soluto concentrada em um dado ponto de um domínio de fluxo em aqüífero satu- 




Figura 3 - Ilustrações de casos de assimetria entre bacias hidrográficas e hidrogeológicas. A) assimetria em sistema cárstico devida à posição relativa entre os sumidouros e a surgência; B) assimetria devida a quebra acentuada de relevo; $C$ ) assimetria devida à presença de zonas drenantes representadas por anisotropias planares (falhas/fraturas abertas) e D) assimetria devida à presença de camada impermeável.

rado (Manoel Filho 1997), podendo ser caracterizado por sua densidade, concentração, cor, ou qualquer outra propriedade.

O estudo de traçadores em poços permite a obtenção de informações como a velocidade da água e o padrão geral do fluxo. Porém, os ensaios com traçador apresentam resultados válidos apenas localmente, não podendo ser extrapolados para todo o aqüífero, a não ser que se conheça previamente a homogeneidade do sistema ou que se realizem estudos em um grande número de poços.

A partir de ensaios com traçadores é possível determinar-se ainda os tipos de dispersores de água subterrânea. A dispersão produzida pelas variações de velocidade em escala microscópica no espaço poroso é chamada de dispersão mecânica. A dispersão transversal, que ocorre na ausência de movimento ou a velocidades muito baixas, é atribuída à difusão molecular, resultante da movimentação aleatória das moléculas de uma zona de mais alta concentração para uma zona de mais baixa concentração. A dispersão hidrodinâmica por sua vez, corresponde à junção desses dois fenômenos. Por outro lado, o movimento do traçador com velocidade média no meio saturado dá-se o nome de convecção ou advecção. Além desses, vários outros fenômenos podem alterar a distribuição da concentração do traçador à medida que ele se move no meio aqüífero como, por exemplo, a ocorrência de trocas iônicas ou decaimento radioativo (Manoel Filho 1997).

Como os estudos de traçadores dependem de dados de potenciometria e de acesso direto ao aqüífero (a partir de poços ou por pontos de sumidouros em sistemas cársticos), seus resultados representam uma excelente ferramenta para a delimitação das bacias em subsuperfície (Fig. 3A).

Esses estudos permitem um refinamento dos limites determinados por outros métodos e também possibilitam definir as variações dos limites em função do bombeamento de determinados aqüíferos livres sob regime transitório de explotação.

Geoquímica Isotópica A água subterrânea aumenta sua mineralização à medida que incorpora íons dos solos e rochas através dos quais percola. Essas reações de dissolução são favorecidas por fatores como a baixa velocidade de circulação da água no aqüífero, maiores condições de pressão e temperatura, reatividade relativa das rochas, além da concentração de gases incorporados ao atravessar solos não saturados (Santos 1997).

A concentração de sais nas águas subterrâneas está intimamente relacionada ao sistema de fluxo hidrogeológico dominante. O fluxo local ocorre onde as áreas de recarga e descarga são próximas, apresenta restrito tempo de residência (águas jovens), sendo, portanto, águas pouco mineralizadas. No sistema de fluxo intermediário existe pelo menos um sistema de fluxo hidrogeológico local entre a água de recarga e descarga, o que resulta em mineralização relativamente baixa. Já o fluxo regional relaciona-se a situações onde a área de recarga é o divisor da bacia e a área de descarga o vale principal, sendo assim um sistema de maior residência (águas mais antigas) e muito mais mineralizado. Assim, a concentração de sais nas águas subterrâneas é em geral maior que o das águas superficiais.

Os padrões de fluxo são controlados pela razão profundidade/comprimento da bacia onde quanto maior essa razão, maior a tendência do fluxo ser regional, e ainda pelo padrão de relevo da bacia onde, quanto mais plano, maior a tendência do desenvolvimento de fluxo regional.

Para a determinação das idades das águas subterrâneas são utilizados isótopos radiogênicos, através dos quais pode-se determinar o tempo decorrido entre a recarga da formação aqǘf́ra e a amostragem de água. Essa datação é possível por que os elementos radioati- 


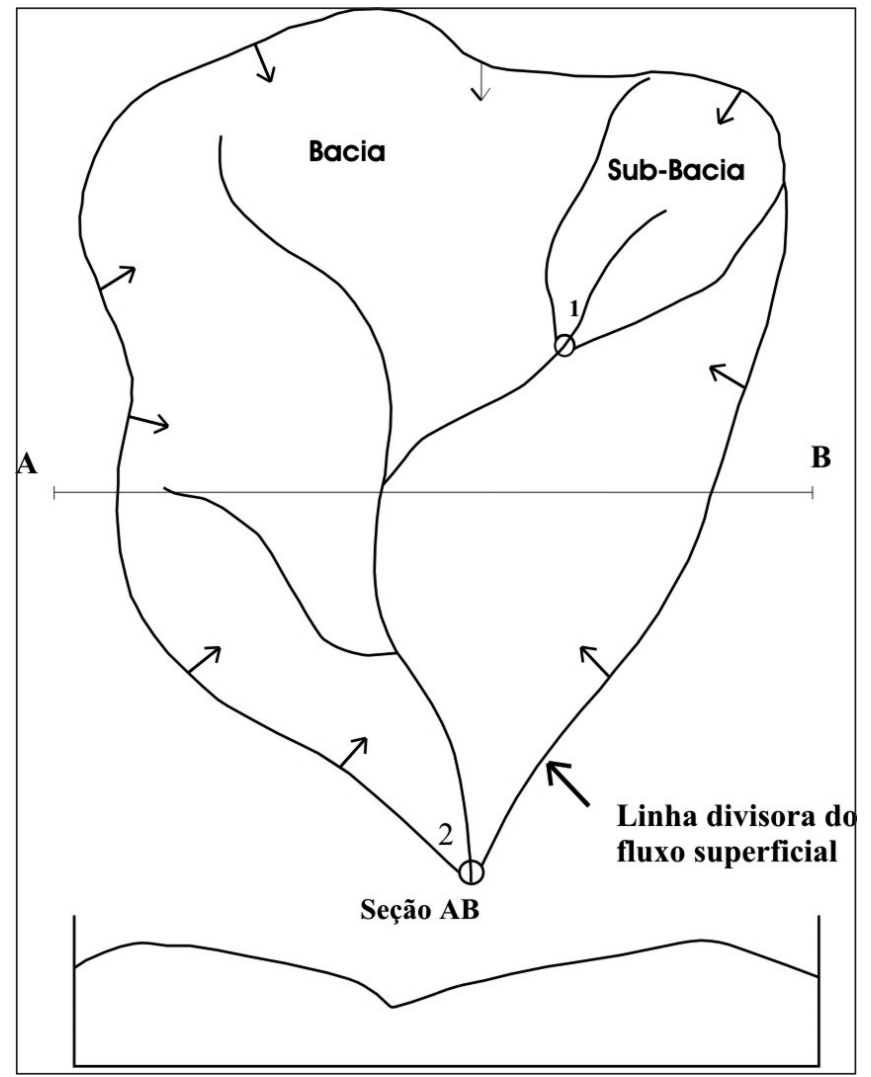

Figura 4 - Representação esquemática em planta e respectiva seção de uma bacia e sub-bacia hidrográfica. Nos casos em que os demais parâmetros do meio físico (solos, relevo, precipitação) são similares, as vazões nos pontos 1 e 2 são proporcionais às áreas de drenagem.

vos, naturalmente presentes na água subterrânea como é o caso do carbono-14, do trítio e de outros, decaem gradualmente em função de sua meia vida.

Assim, o conhecimento da idade das águas e de alguns parâmetros hidrodinâmicos e dimensionais do aqüífero (condutividade hidráulica, porosidade eficaz, coeficiente de armazenamento, espessura saturada e gradiente) permite determinar a ordem de grandeza das distâncias das áreas de recarga, o que pode auxiliar na determinação dos limites das bacias hidrogeológicas e a comparação com os limites das bacias hidrográficas em superfície.

Análise de Lineamentos $\mathrm{O}$ estudo de lineamentos representa uma importante ferramenta para a delimitação de bacias hidrogeológicas. As falhas e fraturas muitas vezes geram situações onde há inversão de fluxo, drenando a água subterrânea em sentido oposto ao da inclinação do terreno, causando assim, descontinuidades entre as bacias hidrogeológicas e hidrográficas.

$\mathrm{O}$ estudo dos lineamentos é realizado a partir da análise de fotografias aéreas ou de imagens orbitais dependendo da escala do estudo.

Os lineamentos são feições planares verticais alinhadas, identificadas principalmente a partir de feições como drenagens retilíneas, quebras de relevo alinhado, mudanças bruscas e retilíneas da vegetação ou de tipos de solo, deslocamentos de cristas, dolinas alinhadas e alongadas, etc.

A correta individualização de falhas e fraturas é de grande importância nos estudos de delimitação de bacias hidrográficas, já que muitas vezes permite descobrir situações onde há inversão de fluxo. Essa situação é marcante nos casos em que cursos fluviais alinhados nascem em superfícies aplainadas e drenam em direção $\mathrm{a}$ áreas rebaixadas adjacentes.

Estudos Geofísicos As investigações geofísicas são métodos de estudo indiretos, onde a partir de medições de grandezas físicas na superfície ou acima da superfície do terreno, é possível a obtenção de informações das condições geológicas e hidrológicas subsuperficiais de forma rápida e a custos reduzidos (Cavalcanti et al. 2001).

Através dos métodos geofísicos, obtém-se informações de grandezas físicas que são interpretadas buscando o conhecimento de estruturas, presença de água, presença e distribuição de mineralizações, etc. As metodologias variam em função das grandezas avaliadas, que são relacionadas à resistência à passagem de corrente elétrica, propagação de correntes secundárias geradas por campos eletromagnéticos, contraste de densidade, elasticidade do meio, dentre outras (Luiz \& Silva 1973).

Através dos métodos geofísicos é possível estabelecer regiões favoráveis ao acúmulo de água subterrânea. Nesse caso, qualquer método geofísico capaz de informar sobre aspectos como estruturas e litotipos propícios a essa acumulação pode ser aplicado satisfatoriamente (Feitosa 1997).

Os métodos mais aplicáveis aos estudos visando à delimitação das bacias hidrogeológicas devem possibilitar a definição do limite entre as zonas não saturada e saturada, ou seja, o método deve ser capaz de mapear a superfície freática. Uma vez delimitadas as cargas piezométricas no aqüífero, pode-se então mapear as assimetrias eventualmente existentes entre as bacias hidrográficas e hidrogeológicas.

O método da eletrorresistividade é o mais indicado para esse fim e deve ser aplicado sempre que for necessária a definição precisa dos limites de bacias hidrogeológicas, notadamente em estudos de contaminação de aqüíferos, em pequenos sítios onde são necessários estudos em grande escala.

\section{IMPLICAÇÕES}

Gestão Integrada A crescente demanda de água subterrânea no Brasil é resultante do processo de diversificação da economia e da urbanização, estimulados pelo aumento populacional (Tundisi 2003). A concentração da população nos grandes centros e o crescimento econômico resultam na degradação da qualidade da água superficial, induzindo a explotação da água subterrânea e tornando este recurso cada vez mais escasso.

Isso ocorre por que a água subterrânea apresenta diversas vantagens sobre os mananciais de superfície, como o fato de serem menos sujeitas aos proces- 


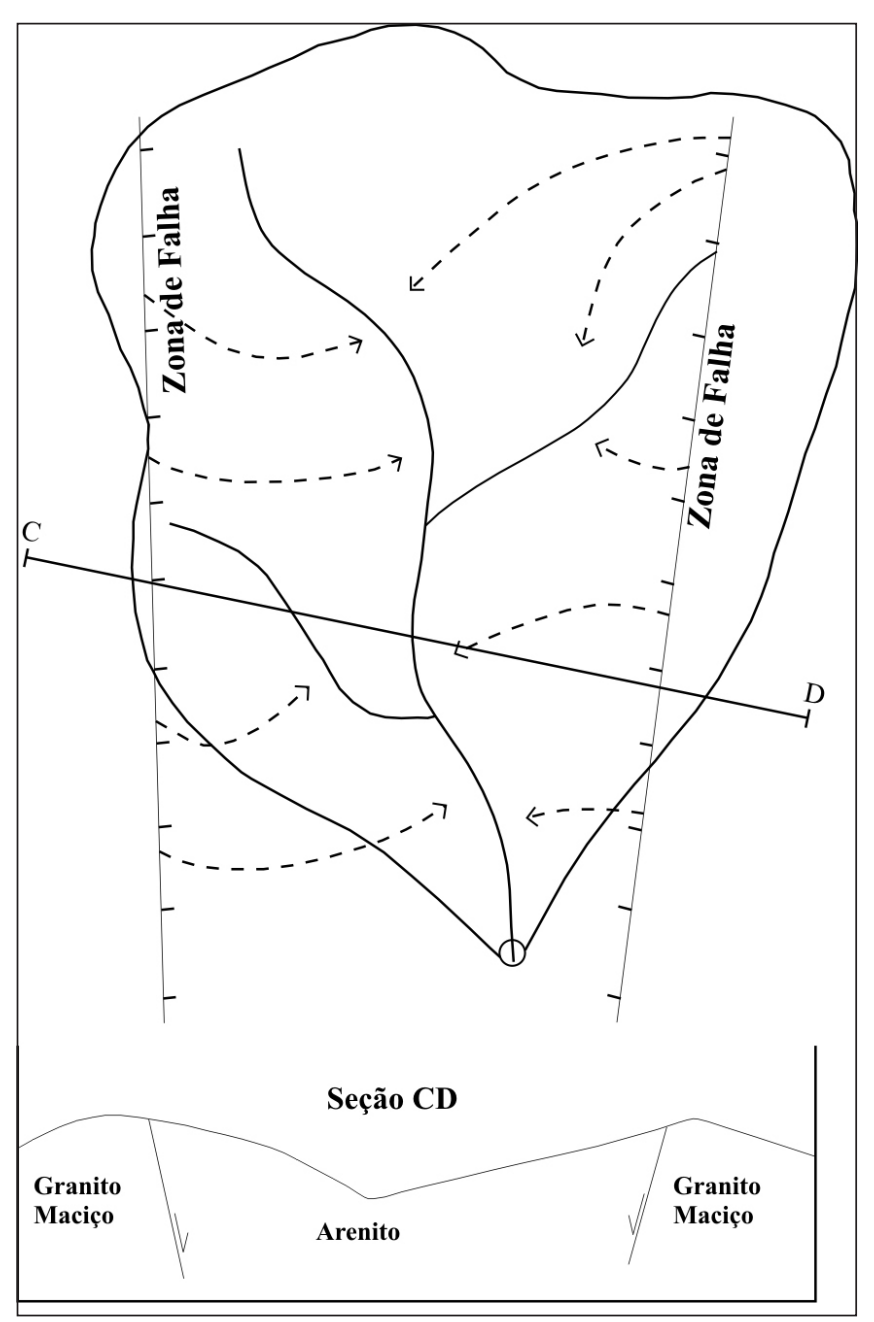

Figura 5 - Representação esquemática em planta e em seção ilustrando a complexidade da definição de exutórios em bacias hidrogeológicas. Considerando que os planos de falhas limitam a bacia hidrogeológica, os exutórios são representados pelos segmentos de canais que formam a rede de drenagem superficial (as linhas pontilhadas representam o fluxo subterrâneo).

sos de evaporação, das obras de captação serem menos onerosas e mais rápida, de dispensarem tratamentos químicos, do sistema ser mais bem protegido de eventuais poluições, etc. Porém, apesar dessas vantagens as águas subterrâneas apresentam também algumas desvantagens, como por exemplo, lenta recarga do aqüífero, possibilidade de sobrexplotação, possibilidade de resultar em subsidência de terrenos cársticos, elevado consumo de energia, alto custo da manutenção preventiva, dentre outras. Assim, o ideal é que haja um planejamento e gestão integrada dos recursos hídricos superficiais e subterrâneos visando a utilização mais racional, econômica e a manutenção da qualidade da água (Costa 1997).

O conhecimento prévio e bem estabelecido das possíveis assimetrias existentes entre os limites das bacias hidrogeológica e hidrográfica superimpostas torna-se essencial, já que, na gestão integrada dos recursos hídricos deve ser considerado que o aqüífero e o respectivo curso d'água superficial façam parte de uma mesma unidade de gestão. Portanto, caso o limite da bacia hidrogeológica seja diferente daquele da bacia hidrográfica, ou ainda, se essa possuir mais de uma bacia hidrográfica sobreposta, um planejamento mais detalhado é necessário para o estabelecimento de uma gestão correta dos recursos hídricos.

A gestão dos recursos hídricos ainda representa um grande desafio para o Brasil, contudo avanços significativos têm sido obtidos. Com a proposição, por meio da Câmara Técnica de Águas Subterrâneas, das resoluções Números 15 e 22, aprovadas pelo Conselho Nacional de Águas Subterrâneas, respectivamente em 2001 e 2002, foi estabelecida uma orientação com relação ao gerenciamento integrado dos recursos hídricos e alertado para a necessidade de inserção da água subterrânea centrada na abordagem dos aqüíferos, que ainda não estão devidamente delimitados, dentro de uma visão sistêmica das potenciais áreas de recarga, trânsito e descarga, bem como suas diversas funções, e não somente a de abastecimento de água (CNRH 2001 e 2002).

As diretrizes para a gestão dos recursos hídricos no Brasil são apresentadas na Lei Federal 9.433/97, porém na prática, só as águas superficiais têm sido objeto das análises de gerenciamento. Falta então, enfocar não somente as bacias hidrográficas, mas também sua forma de gerenciamento integrado, considerando a parcela de água que recarrega os aqǘferos ou ainda os fluxos subterrâneos que mantêm a perenidade de muitos rios (Rebouças 2005).

Portanto, a única forma de se proceder, implementar e viabilizar de forma eficiente a gestão integrada dos recursos hídricos (águas superficiais e subterrâneas) é a partir do conhecimento dos limites das bacias hidrográficas e hidrogeológicas.

Aqüíferos Transfronteiriços Assim como os rios, os aqüíferos também atravessam fronteiras de estados, de municípios e até de países, como é o caso do Sistema Aqüífero Guarani que possui dimensões continentais abrangendo o Brasil, Paraguai, Uruguai e Argentina (Gastmans \& Kiang 2005), podendo assim ser considerado o maior manancial de água doce subterrânea transfronteiriço do mundo.

Como os limites das bacias hidrográficas (serras ou divisores de águas) são comumente utilizados como limites geopolíticos é comum a possibilidade de que os limites entre os divisores de águas superficiais sejam diferentes dos divisores das águas nos aqüíferos. No caso de aqüíferos intergranulares que ocupam amplas áreas geográficas, é comum que, pelo menos do ponto de vista estadual, representem sistemas transfronteiriços.

Ao contrário dos mananciais superficiais, o conhecimento acerca dos reservatórios subterrâneos ainda é muito deficiente. Assim, é necessário identificar os limites da bacia hidrogeológica durante os estudos que objetivam medir e analisar a quantidade e a qualidade da sua água. Essa caracterização só é possível com a 
definição precisa da assimetria entre bacias subterrâneas e superficiais e de seus limites.

Aspectos Legais O projeto de Emenda Constitucional sobre as águas subterrâneas, submetido à aprovação no Congresso Nacional, pretende alterar a dominialidade das águas subterrâneas (Amore 2002).

Segundo o artigo 20, inciso III da Constituição Federal de 1988, "são bens da União: os lagos, rios e quaisquer correntes de água em terrenos de seu domínio, ou que banhem mais de um Estado, sirvam de limites com outros países, ou se estendam a território estrangeiro ou dele provenham, bem como os terrenos marginais e as praias fluviais". Por outro lado, segundo o Artigo 26, inciso I, "incluem-se entre os bens dos Estados: as águas superficiais ou subterrâneas, fluentes, emergentes e em depósito, ressalvadas, neste caso, na forma da lei, as decorrentes de obras da União". Assim, para um mesmo recurso hídrico subterrâneo tem-se uma dúbia interpretação jurídico-institucional.

A solução proposta pelo Projeto de Emenda Constitucional para a questão da dominialidade das águas subterrâneas tem por base tratamento semelhante ao dispensado às águas superficiais. Dessa forma, os aqüíferos transfronteiriços do ponto de vista das fronteiras de nações e estados federados serão federais, enquanto aqueles restritos às fronteiras do estado serão gerenciados pelos organismos do poder público estadual. Com isso, apesar da possível descentralização e desconcentração do gerenciamento hídrico, pode se tornar possível a gestão compartilhada entre estados, a adoção de mecanismos de solução de conflitos entre estados competindo por recursos do mesmo aqüífero, ou ainda o estabelecimento de questões relativas à segurança nacional de aqüíferos transfronteiriços (Amore 2002).

A Lei 9.433 (Brasil 1997), conhecida como lei das águas, incorporou a dominialidade das águas subterrâneas, entendida pela Constituição de 1988 (Brasil 1988) e determinou a bacia hidrográfica como unidade de aplicação da política de recursos hídricos. A dúvida que surge em torno dessa lei é se a política nacional de recursos hídricos também se refere às águas subterrâneas. Ou ainda, tendo-se a bacia hidrográfica como unidade de gestão, como ficariam os casos em que os limites das bacias hidrogeológicas e hidrográficas não coincidem.

Assim, com relação à questão das águas subterrâneas no Brasil, ainda há muito a ser discutido, principalmente no contexto atual de agravamento da escassez e da qualidade da água, e incremento do uso dos mananciais subterrâneos. Para tanto, a definição dos limites das bacias hidrogeológicas/hidrográficas é uma importante questão a ser considerada, visto que poderá levar a distorções na definição dos responsáveis pela gestão dos sistemas aqüíferos quando os limites das bacias hidrográficas e hidrogeológicas forem assimétricos. Na realidade, seria preciso ampliar o conhecimento científico sobre o comportamento e distribuição dos recursos hídricos antes de implementar políticas de gestão, evitando-se assim a elaboração futura de nova legislação para regulamentar a questão.

Definição de Perímetro de Proteção de Poços O perímetro de proteção de poços (PPP) e obras de captação pode ser entendido como a área superficial ou subsuperficial nas adjacências de um poço, nascente ou bateria de poços, onde há risco de que contaminantes presentes se movimentem e os atinjam. O PPP é então delineado com o intuito de restringir a ocupação humana ou de atividades potencialmente poluidoras nas áreas de recarga dos aqüíferos, chamadas de zonas de captura. A dimensão e a forma do PPP depende das características hidrogeológicas do sistema aqüífero envolvido e das características operacionais do sistema de bombeamento aplicado à captação (Kohnke 2001).

Modelos numéricos já desenvolvidos permitem representar os aspectos dos sistemas aqǘf́ros em subsuperfície. Dentre alguns programas computacionais que simulam os modelos numéricos de fluxo de água subterrânea, pode-se citar o MODFLOW (Harbaugh et al. 2000), que foi desenvolvido para simular fluxos de águas subterrâneas na zona saturada de aqüíferos intergranulares, não levando em consideração variações na temperatura e densidade do fluxo. Já o programa MODPATH (Pollock 1994), simula a movimentação de partículas de acordo com o fluxo calculado pelo MODFLOW, sendo, portanto, a ferramenta mais utilizada, juntamente com modelos de fluxo de águas subterrâneas, para o estabelecimento de PPPs (Kohnke 2001). Modelos como o FEFLOW (Diersch 2002) objetivam a modelagem em sistemas aqüíferos anisotrópicos e também são aplicados para determinação do PPP em sistemas cristalinos.

Um dos parâmetros a ser considerado na avaliação da exploração dos recursos hídricos é a vulnerabilidade do sistema aqüífero, definido através da identificação de áreas do aqüífero que se encontram expostas, cobertas por solo muito permeável ou ainda associados a fraturas ou estruturas do tipo cársticas. Essas áreas representam porções onde o risco de contaminação é ainda maior (Kohnke 2001).

Outro fator importante a ser considerado é a definição dos limites da bacia hidrogeológica, que devem ser inclusive monitorados, já que podem sofrer modificações em função da sobrexplotação do aqüífero. $\mathrm{O}$ estabelecimento dos limites das bacias hidrogeológicas pode levar a restrições no desenvolvimento de determinadas atividades e modificações na caracterização dos possíveis usos da água, constituindo-se, assim, em mais um procedimento a ser considerado nesse tipo de avaliação.

Estudos de Aqüíferos Contaminados Lobo-Ferreira (1999) e Cabral (1997) conceituam vulnerabilidade como a sensibilidade da qualidade das águas subterrâneas a uma determinada carga poluente, a qual pode ser definida pelas características intrínsecas do aqüífero. Assim, o termo vulnerabilidade não corresponde ao risco de poluição, uma vez que este último depende tanto da vulnerabilidade quanto da existência de cargas po- 
luentes significativas que possam penetrar no ambiente subterrâneo, sendo possível a ocorrência de casos em que um aqüífero apresenta um alto índice de vulnerabilidade, porém, sem risco de poluição (Lobo-Ferreira 1998).

A contaminação da água subterrânea pode ter suas origens relacionadas a diversos processos que mais comumente estão relacionados a atividades domésticas, agrícolas ou industriais (Manoel Filho 1997). Segundo Fetter (1993), as fontes de contaminação podem ser diferenciadas em fontes projetadas para recepção de substâncias, como é o caso das fossas sépticas e poços de injeção, fontes projetadas para armazenar, tratar ou receber substâncias, como aterros sanitários; fontes projetadas para reter substâncias durante transporte, como por exemplo, os vazamentos de oleodutos; fontes produtoras de outras substâncias em função de outras atividades, caso da aplicação de fertilizantes na agricultura; fontes que podem conduzir a água contaminada, como poços escavados abandonados utilizados como receptores de lixo; e finalmente, fontes naturais ligadas a atividade antrópica, se enquadrando nesse caso, as interações da água superficial contaminada com a subterrânea.

Os estudos de aqüíferos contaminados exigem análises detalhadas, com a aplicação de diversas ferramentas que possibilitam a identificação da causa e da proveniência da contaminação, bem como a seleção das tecnologias de reabilitação mais adequadas. Nesses estudos, busca-se obter informações diretas e indiretas do aqüífero, sendo para tanto, utilizadas técnicas de amostragem de água para análise geoquímica e instalação de piezômetros para monitoramento, além da aplicação de métodos geofísicos e análises geomorfológicas do terreno. A partir desse ponto, e conhecendo-se a delimitação precisa da bacia hidrogeológica associada ao aqüífero, torna-se possível a melhor compreensão dos caminhos percorridos pelos contaminantes e, assim, permitir a aplicação das ações de remediação mais adequadas.

AVALIAÇÃO DE CASOS O presente item não visa detalhar casos onde há assimetria entre as bacias, mas apenas apresentá-los como exemplos de diferentes escalas e causados por diferentes controles.

O Sistema Aqüífero Guarani (SAG) é representado por um conjunto de arenitos com distribuição continental e ocorre em território de vários países. Como existem áreas de recarga situadas em um dos países com águas que fluem para os outros, esse sistema é considerado transfronteiriço e, como há várias bacias hidrográficas distribuídas na superfície do terreno nos diversos países, pode-se afirmar que há forte assimetria entre a bacia hidrogeológica do SAG e as bacias hidrográficas que a recobre.

Em âmbito de limite de estados o Sistema Aqüífero Urucuia (SAU) pode ser citado como um excelente exemplo de assimetria de bacias hidrogeológica e hidrográfica. Esse sistema ocorre ao longo do oeste do estado da Bahia no limite com os estado de Goiás e Tocantins (Gaspar \& Campos 2005). Nesse caso o limite entre os estados é determinado pela Serra Geral de Goiás, que perfaz o limite hidrográfico entre as águas das bacias do São Francisco (com drenagem para leste) e águas da Bacia do Tocantins (que drenam para oeste). Apesar do limite hidrográfico ser definido pela feição fisiográfica, o limite do fluxo subterrâneo se dá a cerca de 20 quilômetros para leste, de forma que parte das águas subterrâneas infiltradas no estado da Bahia drenem em direção à Bacia do Tocantins, compondo uma típica assimetria entre a bacia superficial e a bacia subterrânea.

O Sistema Aqüífero Canastra (SAC) distribuído no território do Distrito Federal também apresenta situações onde as bacias são assimétricas. Na região Chapada do São Bartolomeu no setor central do DF, dados hidrológicos de vazões médias e regularização de vazões comprovam que os limites entre as bacias hidrogeológica e hidrográfica locais não se sobrepõem. Considerando a mesma área de drenagem, os córregos que drenam em direção sudoeste são representados por drenagens intermitentes e de baixa vazão média, enquanto o Córrego Estanislau que drena em direção a sudeste é perene com vazão específica elevada. Esse arranjo sugere um deslocamento para nordeste da linha divisora da bacia hidrogeológica, com relação ao limite hidrográfico determinado pela avaliação das curvas de nível.

CONSIDERAÇÕES FINAIS A delimitação das bacias hidrogeológicas é fundamental para a avaliação de inúmeros aspectos em estudos sobre as águas subterrâneas, notadamente questões sobre risco de contaminação dos aqüíferos, remediação de aqüíferos, estimativa de reservas hídricas, determinação de padrões de fluxo e definição da dominialidade das águas subterrâneas. Todos os enfoques sobre o gerenciamento dos mananciais subterrâneos devem passar pela limitação física dos aqüíferos.

Os estudos que envolvem os conceitos, os critérios de delimitação e os tipos de assimetria entre as bacias hidrográficas e hidrogeológicas ainda são pouco desenvolvidos. Com o aumento progressivo do uso das águas subterrâneas é importante que esse tipo de avaliação seja intensificado para dar suporte às pesquisas sobre os aqǘf́reros, suas áreas de recarga, exutórios e sua gestão.

Os sistemas aqüíferos homogêneos, isotrópicos e não confinados comumente apresentam limites simétricos entre as bacias hidrográfica e hidrogeológica, isto é, as linhas divisoras das águas superficiais são sobrepostas ao divisor das águas em subsuperfície. A assimetria entre os limites das bacias é mais comumente observada em sistemas aqüíferos heterogêneos e anisotrópicos.

Ao contrário das bacias hidrográficas, os limites das bacias hidrogeológicas não são fixos e podem sofrer variações no tempo em função do regime de bombeamento dos aqüíferos. As mudanças dos limites são mais facilmente percebidas em estudos de detalhe. 
Os modelos matemáticos e computacionais utilizados como ferramentas para os estudos de aqüíferos necessitam, como um dos parâmetros obrigatórios de entrada de dados (input data), informações sobre os limites do aqüífero. Muitos casos onde a modelagem gera resultados insatisfatórios são devidos ao fornecimento equivocado das fronteiras do aqüífero, que, em muitos casos, coincidem com os próprios limites das bacias e sub-bacias hidrogeológicas.

\section{Referências}

Amore L. 2002. A dominialidade das águas subterrâneas e a comunidade técnico-científica brasileira. ABAS informa, 129:11.

Brasil. 1988. Constituição da República Federativa do Brasil. Congresso Nacional, Brasília.

Brasil. 1997. Lei $n^{\circ}$ 9.433, de 8 de janeiro de 1997. Diário Oficial da União, 9 de janeiro de 1997.

Cabral J. 1997. Movimento das Águas Subterrâneas. In: A.C.F. Feitosa \& J.Manoel Filho (ed.) Hidrogeologia: Conceitos e aplicações. Fortaleza, CPRM/LABHID, 3551.

Cavalcanti S.S., Sato H.K., Lima O.A.L. 2001. Geofísica elétrica na caracterização da hidrologia subterrânea na região do Aterro Metropolitano Centro, Salvador, Bahia. Brazilian Journal of Geophysics, 19(2):155-168.

Clark B.T., Burkardt N., King D. 2005. Watershed management and organization dynamics: nationwide findings and regional variation. Environmental Management 36(2):297-310.

CNRH 2001. Resolução $n^{\circ} 15$, de 11 de janeiro de 2001. Conselho Nacional de Recursos Hídricos, Diário Oficial da União, publicado em 22 de janeiro de 2001.

CNRH 2002. Resolução $n^{\circ} 22$, de 24 de maio de 2002. Conselho Nacional de Recursos Hídricos, Diário Oficial da União, publicado em 04 de julho de 2002.

Costa W.D. 1997. Uso e Gestão de água Subterrânea. In: A.C.F. Feitosa \& J. Manoel Filho (ed.) Hidrogeologia: Conceitos e aplicações. Fortaleza, CPRM/LABHID, 341-364.

Diersch H.J.G. 2002. FEFLOW finite element subsurface flow and transport simulation system - user's manual, Release 5.0. Wasy, Berlin, Germany.

Feitosa E.C. 1997. Pesquisa de Água Subterrânea. In: A.C.F. Feitosa \& J. Manoel Filho (ed.) Hidrogeologia: Conceitos e aplicações. Fortaleza, CPRM/LABHID, 53-80.

Fetter, C.W. 1993. Contaminant hydrogeology. Upper Saddle River. Prentice Hall., 458 p.

Gaspar M.T.P. \& Campos J.E.G. 2005. O Sistema Aqüífero Urucuia. In: SBG, Simpósio sobre o Cráton do São Francisco, 3, Salvador, Anais, cd rom.

Gastmans D. \& Kiang C.H. 2005. Avaliação da hidrogeologia e hidroquímica do Sistema Aqüífero Guarani (SAG) no estado de Mato Grosso do Sul. Águas Subterrâneas, 19(1):35-48.

Harbaugh A.W., Banta E.R., Hill M.C., McDonald M.G. 2000. MODFLOW-2000, the U.S. Geological Survey modular ground-water model - User guide to modula- rization concepts and the Ground-Water Flow Process. U.S.G.S. Survey Open-File Report 00-92, 121 p.

Kohnke M.W. 2001. Atenuação natural de contaminantes, metodologias para a delimitação do perímetro de proteção de poços (PPP). ABAS Informa, S.Paulo, 121:9-10.

Lobo-Ferreira J.P. 1998. Vulnerabilidade à poluição de águas subterrâneas: fundamentos e conceitos para uma melhor gestão e proteção dos aqüíferos de Portugal. In: APRH, Congresso da Água, 4, Lisboa, comunicações, 1-16.

Lobo-Ferreira J.P. 1999. The European Union experience on groundwater vulnerability assessment and mapping. COASTIN, A Coastal Policy Research Newsletter, New Delhi, 1:8-10.

Luiz J.G. \& Silva L.M.C.S. 1973. Geofísica de Prospecção. Editora Universitária UFPA-Editora CEJUP, Belém, $311 \mathrm{p}$.

Manoel Filho J. 1997. Contaminação das águas subterrâneas. In: A.C.F. Feitosa \& J. Manoel Filho (ed.) Hidrogeologia: Conceitos e aplicações. Fortaleza, CPRM/LABHID, 109-132.

Pollock D.W. 1994. User's Guide for MODPATH/MODPATH-PLOT, Version 3: A particle tracking post-processing package for MODFLOW, the U.S. Geological Survey finite-difference groundwater flow model. U.S. Geological Survey Open-File Report 94-464.

Rebouças A.C. 2005. Água subterrânea no sistema nacional de gerenciamento dos recursos hídricos. ABAS Informa, São Paulo, 154:3.

Rennó D. C. \& Soares J. V. 2001. Discretização espacial de bacias hidrográficas. In: INPE, Simpósio Brasileiro de Sensoriamento Remoto, 10, Foz do Iguaçu, Anais, 485492.

Rennó D. C. 2004. Construção de um sistema de análise e simulação hidrológica: aplicação a bacias hidrográficas. Tese de Doutoramento, Instituto Nacional de Pesquisas Espaciais, INPE, 148p.

Santos C.A. 1997. Noções de Hidroquímica. In: A.C.F. Feitosa \& J. Manoel Filho (ed.) Hidrogeologia: Conceitos e aplicações. Fortaleza, CPRM/LABHID, 81-108.

Tiedman R.C., Goode D.J., e Hsieh P.A. 1998. Characterizing a ground water basin in New England Mountain and valley terrain. Ground Water, 36(4):611-621.

Tundisi J.G. 2003. Ciclo Hidrológico e Gerenciamento Integrado. Ciência e Cultura, 55(4):31-33.

Manuscrito AE-011/2006

Recebido em 10 de março de 2006 Aceito em 13 de março de 2007 